\title{
Laser Propulsion Market-Creating Innovation
}

\author{
louri Pigulevski \\ DLTECH Institute, Yverdon-les-Bains, Switzerland.
}

\begin{abstract}
Laser propulsion (LP) technology state of the art is discussed. LP innovation is defined. Disruptive opportunity for LP innovation is identified. LP future development and its market positioning as a market-creating innovation and potential implications to the space industry are envisioned.
\end{abstract}

\section{INTRODUCTION}

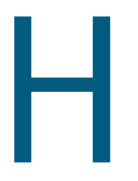

istory of laser propulsion (LP) starts in the 1970s with the pioneering works of Kantrowitz ${ }^{1}$ and Bunkin and Prokhorov. ${ }^{2}$ The International Symposia on the Beamed Energy Propulsion held regularly since 2002 contributed a lot to the scientific advances in the various aspects of LP. Various prototypes of laser propulsion engines (LPEs) were developed since then. ${ }^{3}$ Notably, in 2002-2006, the experiments of launching the LightCraft designed by Myrabo and Lewis by means of the pulse-periodic $\mathrm{CO}_{2}$ laser grabbed attention of the scientific community and general public. ${ }^{4}$

\section{LP TECHNOLOGY}

Until recently, mostly the subsonic LP was under scientific consideration. Some promising subsonic LPE designs were created, and the necessity of the very high average power technological laser to enable LP was established.

The LP state-of-the-art technology is analyzed in several publications. $^{3,5}$ Same as with the ion propulsion, the LPspecific impulse (Isp) can go over 10,000 s. It was estimated that launching a payload of about $10 \mathrm{~kg}$ into the low Earth orbit (LEO) would require a laser beam of $1 \mathrm{MW}$ of average power. ${ }^{5}$

The recent theoretical research by Rezunkov and Schmidt in the field of supersonic LP resulted in the new and much more efficient LP technique. ${ }^{6}$ Although not eliminating a necessity of using the very high average power laser $(\sim 1 \mathrm{MW})$, it promises a prospect of launching into orbit the significantly heavier payloads than those earlier estimated for the subsonic
LP, thus increasing the practical interest toward the LP technology as a potentially cheap and ecologically clean way of not so large payload delivery to the Earth orbit. It also strongly urges construction of a very high average power laser for comprehensive development of the supersonic LP launching system.

\section{HIGH AVERAGE POWER LASERS}

The LP technology development toward its practical availability is intrinsically linked to progress in the high average power lasers' state of the art, which has been reflected in numerous publications and proceedings of scientific conferences. $^{5,7-9}$

Creation of the very high average power technological laser was dreamed of and targeted since the dawn of laser science and technology. So far, the best experimental results were achieved in the mid-1990s by Dymshits et al. who had designed and built the first full-scale working mock-up of the supersonic open-cycle continuous wave (CW) CO laser, which repeatedly demonstrated the average lasing power of around $200 \mathrm{~kW}$ and proved the laser's conceptual workability. ${ }^{10-12}$

While construction of the full-scale $1 \mathrm{MW}$ average power technological supersonic CO laser prototype (further referred to as CODL) is still in progress, the theoretical research produced the mathematical modeling and simulations of the CODL operation in CW and Q-switched modes, followed by the plausible estimates of its operation under various conditions, including the multi-MW laser design. ${ }^{13-17}$ By the wide scope of its technological capabilities, CODL can be classified as a key enabling technology.

State of the art in the field of the high average power commercially available technological lasers is given in the following Table 1 alongside the CODL projected performance.

Currently, the high average power industrial prototype of CODL is being built by DLTECH Institute of Switzerland. Having the CODL eventually operating at the average power levels close to $1 \mathrm{MW}$ will enable the full-scale supersonic LP development and, then, bring it as an enabling tool for LP to the rapidly growing nano-/micro-/minisatellite sector of the launching market. ${ }^{18}$

(c) louri Pigulevski, 2016; Published by Mary Ann Liebert, Inc. This open access article is distributed under the terms of the Creative Commons Attribution Noncommercial License (http://creativecommons.org/licenses/by-nc/4.0/), which permits any noncommercial use, distribution, and reproduction in any medium, provided the original author(s) and the source are credited. 


\begin{tabular}{|c|c|c|c|}
\hline Parameters & $\begin{array}{c}\text { CODL (CO Laser) } \\
\text { Projected }\end{array}$ & $\begin{array}{c}\text { SM61-45 } \\
\left(\mathrm{CO}_{2} \text { Laser }\right)\end{array}$ & $\begin{array}{l}\text { YLS-50000 } \\
\text { IPG (Fiber) }\end{array}$ \\
\hline Wavelength $(\mu)$ & 5 (free lasing mode) & 10,6 & 1,070 \\
\hline Average power (kW) & $\begin{array}{c}>300 \text { up to } 40 \times 1,000 \\
\text { (single module) }^{15}\end{array}$ & $\begin{array}{c}\leq 45 \\
\text { (6 modules) }\end{array}$ & $\begin{array}{l}\leq 50 \text { (dozen } \\
\text { modules) }\end{array}$ \\
\hline $\begin{array}{l}\text { Specific } \\
\text { weight }(\mathrm{kg} / \mathrm{kW})\end{array}$ & $\leq 50$ & $\geq 400$ & $\leq 60$ \\
\hline $\begin{array}{l}\text { Wall-plug } \\
\text { efficiency (\%) }\end{array}$ & $\geq 24$ up to 50 & $\leq 6$ & $\sim 30$ \\
\hline
\end{tabular}

\section{LP INNOVATION PROSPECT ANALYSIS}

Let us imagine for a moment that the MW average power laser is operational and the LP technology is developed and just became available for use.

What type of innovation could be successfully staged based on the LP technology then?

To cogently answer the above question, the LP should be analyzed as an innovation phenomenon. To do so, the concepts of the innovation theories in connection with the LP will be reviewed.

Properly staging an innovation, defining the correct ad hoc business models, and eventually making a great business success out of it involve using a set of concepts and tools, which include the Resources, Processes, and Values framework and Value Chain Evolution theories, the asymmetries of motivation and initial market foothold concepts, the jobs-tobe-done approach, and more. ${ }^{19-25}$

The term innovation is used in this article to denote the economic category and the fundamental market development mechanism.

Innovation is defined here as the process by which newgrowth businesses are created (see pp. 7-8 in Ref. 20).

This is the only definition to be used for the term innovation in this article. Thus, despite being based on the LP technology, laser propulsion innovation (LPI) means, in the current context, neither the technological improvements nor the R\&D results or engineering solutions, but creation of the new or new-growth businesses based on the LP technology.

A sustaining innovation targets demanding high-end customers with better performance than what was previously available (see p. 24 in Ref. 20), while a disruptive innovation, in contrast, attempts to bring to a market a very different value proposition than had been available previously. ${ }^{21}$

The low-end (efficiency) and new-market disruptive innovations are those that enable the low-end (efficiency) and new-market disruptions accordingly. A well-established set of criteria exists to distinguish the types of innovations (see pp. 45-50 in Ref. 20).

It allows defining which type of innovation can and which cannot be successfully staged under a particular set of market circumstances.

Having the LP technology developed and available in the near future will carry, at the very beginning, no practical relation to a mainstream market and therefore will not serve as a basis for sustaining a type of innovation for some time.

Not being sustainable does not automatically make an innovation disruptive. Only if LPI could bring a new market value proposition, then it might qualify for being disruptive.

According to its inherent logic of development, LP will be capable, first, of launching into LEO the payloads of some kilograms ${ }^{5}$ only. Then, very soon, it will achieve the ability to launch dozens of kilograms and, eventually, some hundreds of $\mathrm{kg}$.

\section{MARKET TRENDS AND LPI}

Looking broadly at the current launching services global market picture, we can see that there is a small group of incumbents (NASA, Roskosmos, ESA, ISRO, CNSA, ULA, SNC) who successfully launch objects into space. Majority of their business comes from the state-funded science and military programs, as well as the telecom industry. The incumbents are mostly involved into a sustaining type of innovation, trying to improve their existing launching technologies' reliability and safety to get the high-end customers satisfied and willing to continue paying high premium for their launching services.

Today, the incumbents are capable of launching the payloads of up to dozens of tons into orbit. Lifting a few tons into orbit is routine business. Their launching technologies are designed and honed to do just that. These technologies were not created to serve the very small satellites $(<250 \mathrm{~kg})$ and cannot do it in a cost-efficient manner. In addition, providing launching services to the nano-/micro-/minisatellite niche market is sort of a secondary business of a lower priority for the incumbents because, in comparison with their customary margin rates, it is far less lucrative.

In terms of the payload weight, the launching technological capabilities and services offered today by the incumbents overshoot the launching needs of the very small satellite niche market by a large margin and, simultaneously, underserve them otherwise (price, convenience). These launching services are too expensive and cumbersome and thus severely nonoptimum. The absence of adequate launching technology holds back development of the very small satellite niche market and the connected sectors of telecom and other industries/activities. 
The incumbents' core values and management processes are squarely set on the mainstream market. They are not designed for and, thus, incapable of targeting the niche markets. Their business models do not favor lowering the specific costs of their services too. Generally, no incumbent is interested in a niche market until the market matures and goes mainstream.

Exactly the same set of circumstances provides LPI with a promising market entry point (initial market foothold) through the low-end (efficiency) disruptive innovation opportunity and asymmetry of motivations.

Efficiency innovations help companies make and sell mature established products or services to the same customers at lower prices. ${ }^{25}$ Efficiency innovation is often linked to, but should not be confused with, the efficiency of a technology. Efficiency innovation is commonly achieved by using a lowcost business model (based or not based on a lower cost product or technology), which an entrant company can support, but an incumbent cannot.

During the last decade, several dozen private start-ups were formed worldwide to provide the space industry with the alternative and improved options in launching services. These companies are seeking to establish themselves in the market by making the launching services cheaper, more convenient, and, in some cases, by specifically targeting the low-weight payloads.

For example, the first thing one learns on the Jeff Bezos Blue Origin website is a slogan: "We're working to lower the cost of spaceflight."

To do so, the market entrants are addressing both (1) the existing launching technologies by marginally improving their efficiency (sustaining innovation) and (2) the business models by introducing the disruptive ones (low-end disruptive innovation also called efficiency innovation ${ }^{24,25}$ ). To be on par with the incumbents in (1), the market entrants actively cooperate with the top technical universities and hunt for their best graduates to employ them. When necessary, they can go far to win over the key space engineering personnel from NASA and large aerospace corporations. As for (2), very much in accordance with the modern disruptive innovation theories mentioned earlier, the successful entrants do not borrow the managerial practices and processes from the large incumbent corporations and, normally, do not hire personnel from these corporations to fill the very top managerial positions as doing so could compromise their ability to stick to the disruptive innovation strategy. Some entrants are not as successful as SpaceX not only because they may lack as strong a leadership but also rather because, inadvertently, they often mix into their business strategies and managerial practices those from the large corporations, strategies and practices which squash the start-up's disruptive initiative from inside. The commercial values and operational processes of the market entrants and incumbents do not mix well.

The new space market entrants' commercial activities are often called the New Space, as opposed to the previously fully led and mostly financed by government space activities. The business models and high operational efficiency of the new entrants disrupt to some degree the established incumbents and make them change. For example, NASA was always outsourcing the launching hardware to the private sector, but, today, the recent market entrant SpaceX takes on the whole launching business and demonstrates much higher technological and cost efficiency than NASA-led businesses could ever achieve.

The SpaceX's low-end disruptive innovation in the launching services was based on the business model and sustaining innovations rather than introducing a new launching technology. This is an efficiency innovation. Currently, SpaceX routinely takes on the mainstream launching tasks accorded by NASA such as supplying the ISS (along with a few other NASA private contractors) and putting large satellites into orbit.

In fact, SpaceX just transformed itself from the market entrant into the market incumbent. Having achieved the incumbency, it will tend to innovate rather sustainably than disruptively.

Of course, Elon Musk may embark upon a new-market disruptive innovation (also called market-creating or empowering innovation $^{24,25}$ ) such as the permanent orbital outposts/settlements (planned together with Bigelow Aerospace) or launching swarms of the micro-/minisatellites, thus strongly challenging the scope of demand in global launching services. However, trying to combine the mainstream business and disruptive innovation is a tricky proposition, which, historically, has tripped over some great corporations and market leaders from different domains of industry into oblivion.

At the same time, the launching services targeted by Virgin Galactic (SpaceShipOne) are distinctly different in their nature, product, and business model than those of SpaceX. Virgin Galactic shapes its innovation as mostly a new-market disruption (targeting the nonconsumers). Seemingly, it could also be seen as a low-end disruption of the lucrative space tourism business conducted for the last 20 years from the Russian facilities by Space Adventures, Inc., but, in fact, this is not the case due to their very different market propositions (suborbital flight vs. ISS experience+space walk).

Escape Dynamics, Inc., stands out in a crowd of the conventional launching technology adherents. It deserves a lot of credit as it challenges the conventional propulsion technology paradigm by working on and promoting the beamed propulsion 
(microwaves). Only time will show whether using the microwaves for beamed propulsion is a good choice as it may result in unreasonable energy expenditures per unit of produced thrust.

\section{LPI DISRUPTIVE OPPORTUNITY}

\section{AND MARKET-CREATING POTENTIAL}

Despite the very rapid growth of the market demand ${ }^{18}$ and also widely publicized plans of SpaceX, OneWeb, and Sir R. Branson for launching the loads of the very small satellites, there is no adequate launching technology to address this market niche in a cheap, convenient, and ecologically clean way.

Today, as yesterday, the very small satellites $(<250 \mathrm{~kg})$ are mostly launched into orbit by means of conventional chemical propulsion rockets as the hosted supplementary payloads.

Launching them in bunches, as a secondary payload, does not eliminate the high specific costs of their delivery to orbit.

Launching very small payloads by means of dedicated, small conventional rockets or piloted spaceplanes (Electron by Rocket Labs; Lynx by XCOR Aerospace, ALASA, etc.) results in even higher specific launching costs.

It should be clearly understood that this is not an engineering problem, which can be solved within the existing launching propulsion technology paradigm because no engineering solutions can substantially increase the low specific impulse (Isp) of the chemical rocket engines, which is always under $500 \mathrm{~s}$ and practically around $200 \mathrm{~s}$. Thus, any propulsion engineer can tell that significantly lowering the launching costs while using the existing chemical propulsion technology is impossible in principle.

What can be done, at best, within the existing launching propulsion technology paradigm is improving the overall economics of launching into orbit by weight reduction measures, by, probably, introducing multiple uses of spacecraft, and by lowering the manufacturing cost in all segments of the production chain, measures which were and are being vigorously targeted by the launching industry incumbents as part of their ever sustaining innovation agenda.

Hence come Google's balloon and Facebook's drone projects $^{26}$ as attempts to escape the existing launching propulsion technology paradigm and find something supposedly cheaper even if very far from being practically suitable to their end of reaching the underserved 4B people of the Earth's population with mobile telecom and internet services. Often, the other side of a problem is an opportunity.

The above Table 2 of the specific launching to LEO prices by different providers versus projected costs for LP demonstrates the low-end disruptive opportunity for LPI in the very small satellite launching niche market, which, at the very beginning,
Table 2. Launching to LEO specific prices by some providers ${ }^{27}$ versus projected costs for $L P$

\begin{tabular}{l|c} 
Launching System & $(\mathbf{k} \$ \mathbf{k g})$ \\
\hline Laser Propulsion System & $\sim 0.01$ (projected) \\
\hline Falcon Heavy, SpaceX & $\sim 1.7$ (projected) \\
\hline Dnepr, ISC Kosmotras & $\sim 3.4$ \\
\hline Proton M, ILS & $\sim 4.3$ \\
\hline Long March 3B, CNSA & $\sim 4.4$ \\
\hline Falcon 9, SpaceX & $\sim 4.7$ \\
\hline Pegasus XL, O. ATK & $\sim 30$ \\
\hline Electron, Rocket Lab & $\sim 33$ \\
\hline
\end{tabular}

would target substitution of the existing services with the less expensive one:

The table shows that LPI has a lot to do with the efficiency of the underlying LP technology.

The LP technology is so efficient that it can tumble the specific costs of launching small objects into orbit down to a minuscule fraction of the current costs.

By introducing a cheap way of launching small objects into orbit, LPI would enable many of the existing and new consumers of space launching services to have their aspirations and commercial goals fulfilled. It would lead to creation of a new global launching niche market and stimulate fast growth of the multiple related markets and industries such as, to name a few, large-scale manufacturing of the nano-/micro-/minisatellites and all of their components; the telecom and internet new vast regional markets; and the media and content markets, which would foster new growth of the massive downstream consumer markets.

Such a scenario may make the relevant high-tech companies affluent and their employments going through the roof, which in its turn may serve to invigorate the economies and employment rates of some countries. As put by C. Christensen,

“... An efficiency innovation pointed in right directiontoward turning nonconsumption into consumption-becomes a market-creating innovation" and "Market-creating innovations ... transform complicated or costly products so radically that they create a new class of consumers, or a new market." 25 This pertains exactly to LPI.

Being positioned in its initial stage as an efficiency innovation, LPI should be approached and shaped at the later stage as a market-creating innovation (Fig. 1).

Aside from the low cost, some other important factors will contribute to the market-creating LPI. Convenience of using a 


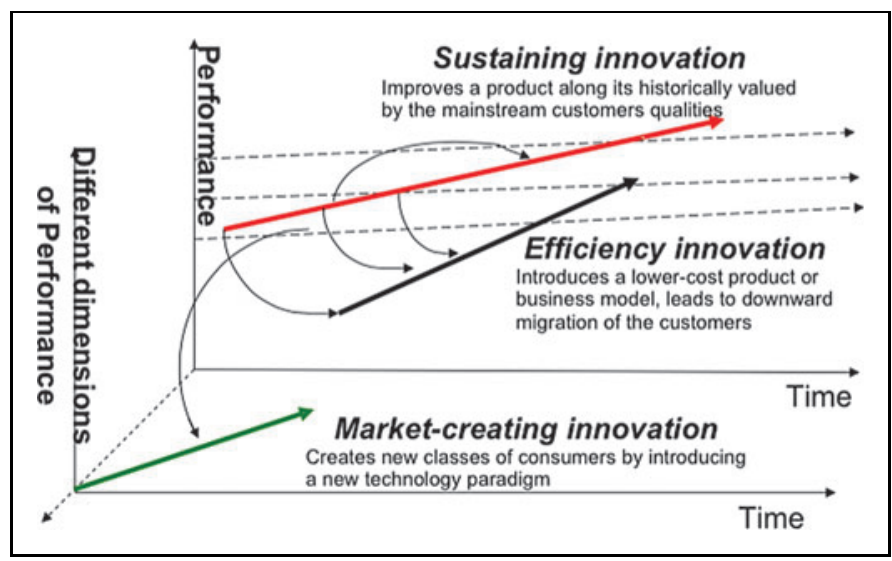

Fig. 1. Efficiency and market-creating laser propulsion innovation (based on the previously published graph $^{20}$ ).

product or service is one of them. LPI will enable the ondemand on a very short notice launching service with any reasonable frequency for the nano-/micro-/minipayloads of standard sizes, which is practically unattainable by means of the conventional launching technologies.

Another quality of high value inherent to LPI is an intrinsic environmental cleanness of the LP technology. In the modern world of highly elevated environmental concerns, it is becoming an important factor in competition for the market.

The absence of the flammable or dangerously explosive components aboard the LP-enabled vehicles frees LPI from potentially severe hazardous accidents, a circumstance which may win the favor of insurance companies.

Being economically suitable for launching the very small payloads into orbit, LP technology allows to position LPI as a valid and, probably, the only realistic way to gradually transform the nascent niche market of the nano-/micro-/ minisatellite launching services, at first, into the quickly growing emerging market, and then into the mainstream one, which should be seen as a main long-term objective of LPI.

The market-creating strategies of LPI will be based on the well-defined approaches. ${ }^{21}$ For example, servicing the ISS and future orbital settlements with rapid on-demand parcel delivery would de facto create the first Space Postal Service. By the way, historically, the Postal Services followed closely the pioneers to the very frontiers.

Even if the maximum weight of a single payload will not soon exceed $100 \mathrm{~kg}$, the LP projected ability to ship the materials and equipment, piece by piece, with any frequency, and cheaply to LEO may make economically viable setting up of the large industrial facilities and settlements at LEO under protection of the magnetic field of Earth from the high-energy cosmic particles.
A first Space Construction Company may appear then to assemble the pieces of the orbital constructions in a Lego-like manner (of course, to let it happen, there are many fundamental technological problems to be resolved first). As a result, in, hopefully, not so distant future, the large satellites and deep space missions will be routinely assembled from small pieces at LEO, and then launched or put into operation right from there, eliminating the painful necessities of overcoming the planetary gravitation and polluting the Earth's atmosphere every time a large payload is launched into orbit in a conventional way.

Creating an efficient and inexpensive transportation link between the Earth's surface and orbit is, arguably, the most critical key factor that will either hold down or let the global space industry quickly develop as all the components of space exploration, including the deep-space travel, heavily depend on availability of the industrial infrastructure, settlements, and spaceports at LEO under protection of the magnetic shield of Earth. LPI may very well help in letting it happen.

\section{CONCLUSIONS}

1. The recently proposed supersonic LP techniques promise a significant increase in the LP thrust. $^{6}$

2. The CODL laser potentially capable of over $1 \mathrm{MW}$ average power output is being built and will become available soon.

3. The exponential growth of demand for launching the very small satellites to LEO provides LPI with an outstanding first market entry point through the low-end disruption opportunity, a type of innovation that historically enjoyed the high rate of success in different industries.

4. Approached and staged further as a new marketcreating innovation, LPI may lead its business proponents to long-term global market leadership.

5. LPI may become a key solution in establishing the reliable and inexpensive bridge between Earth and LEO, thus helping to shape the global space industry for serving better the vital immediate and future needs of humankind and also invigorating its economical development and employment rates.

\section{ACKNOWLEDGMENTS}

Much of the author's gratitude goes to Dr. Y. Rezunkov for his continuous precious advice and materials on the supersonic LP, which helped immensely in writing this article. In addition, the author extends his great appreciation to Prof. Clayton Christensen, whose robust theories of innovation serve as the analytical foundations in this article and whose personal kind attention encouraged the author once to apply them practically. 


\section{AUTHOR DISCLOSURE STATEMENT} No competing financial interests exist.

\section{REFERENCES}

1. Kantrowitz A. Propulsion to orbit by ground-based lasers. Astronaut Aeronaut. 1972;10:74-76.

2. Bunkin F, Prokhorov A. The use of laser power to produce a thrust. Sov Phys Usp. 1976;119:425-446.

3. Rezunkov Y. Laser propulsion, the overview of recent investigations. J Opt Technol. 2007;74:18-39.

4. Myrabo L, Lewis J. LightCraft, Flight Handbook. Burlington, Ontario, Canada: Apogee Books, 2009.

5. Phipps C, et al. Review: Laser-ablation propulsion. J Propul Power. 2010; 26(4):609-637.

6. RezunkovY, SchmidtA. Supersonic laser propulsion. Appl Optics. 2014;53(31):11-18.

7. ESA White Paper. Laser propulsion for ESA missions: Ground to Orbit Project Overview. Instituto Superior Técnico, Lisbon, 2004.

8. Reilly James P. A survey of current high power laser technology and non-DOD applications. International Conference Lasers'96, Portland, Oregon, 1996.

9. International Symposium on High Power Laser Ablation. AIP Conference Proceedings, Vol. 1464, Springer, 2012.

10. Dymshits B, Ivanov G, Mescherskiy A. Technological supersonic e-beam sustained CW CO laser. In: Proceedings of the Conference "Lasers '93," LakeTahoe, NV, 1993, pp. 254-261.

11. Dymshits B, Ivanov G, Mescherskiy A, Kovsh I. CW 200 kW supersonic CO laser. Proc SPIE. 1994;2206:109-120.

12. Johnson R, Dymshits B, Ivanov G, Mescherskiy A, Reilly J, Lander M. Lasermaterial test results from high power carbon monoxide laser. Proc SPIE. 1996;2714:222-228.

13. Dymshits B, Alexandrov B, Belavin V, Koretskiy J. Numerical investigation of energy characteristics of the first overtone generation of a high power supersonic e-beam sustained CO laser. Proc SPIE. 1996;3092:309-312.

14. Alexandrov B, Belavin $V$, Dymshits B, Koretskiy J. Energy and spectral characteristics of a supersonic electron-beam-sustained $\mathrm{CO}$ laser based on the first vibrational overtone and also operating in a selective regime. Quantum Electron. 1997;27(7):584-588.

15. Dymshits B, Alexandrov B. Multi-megawatt supersonic e-beam sustained CW $\mathrm{CO}$ laser: Estimations of the energy characteristics and operating regimes. Proc SPIE. 1997;3092:448-451.
16. Alexandrov B, Belavin V, Dymshits B, Koretsky J. Supersonic e-beam sustained CO laser in the repetitive 0-switched mode. Proc SPIE. 1998;3574: 538-544.

17. Alexandrov B, Belavin V, Dymshits B, Koretsky J. Calculation of the energy and spectral characteristics of a supersonic electron-beam-sustained CO laser with periodic cavity Q-switching. Quantum Electron. 1999;29(4):285-290.

18. Buchen E, Pasquale D. 2014 Nano/Microsatellite Market Assessment. SpaceWorks Enterprises, Inc. (SEI), Atlanta, GA 2014.

19. Porter M. Competitive Strategy: Techniques for Analyzing Industries and Competitors. New York: Free Press, 1980.

20. Christensen C. The Innovator's Dilemma: When New Technologies Cause Great Firms to Fail. Boston, MA, Harvard Business School Press, 1997.

21. Christensen $C$, Raynor M. The Innovator's Solution. Creating and Sustaining Successful Growth. Boston: Harvard Business School Publishing, 2003.

22. Christensen C, Musso C, Anthony S. "Maximizing the Returns from Research." Research-Technology Management. 2004; 47(4).

23. Christensen C, Anthony S, Roth E. Seeing What's Next. Boston: Harvard Business School Press, 2004

24. Christensen C. A Capitalist's Dilemma, Whoever Wins on Tuesday. The New York Times. Nov. 3, 2012

25. Christensen C, Bever D. The capitalist's dilemma. Harvard Business Rev. 2014; 6:62-70 (Available at www.innosight.com/innovation-resources/the-capitalistsdilemma.cfm)

26. Pagliery J. Billionaires battle for the Internet in space. CNN Money. January 21 2015.

27. Financial effort estimations. MarsPedia is an official project of both The Mars Society and the Mars Foundation. 2015. http://www.marspedia.org/index. php?title=Financial_effort_estimation
Address correspondence to: Iouri Pigulevski DLTECH Institute

Avenue des Sciences 3 Yverdon-les-Bains 1400 Switzerland

Email: dltech.ch@gmail.com 